\title{
THE CREATIVE ROLE OF PLASTIC ARTS IN THE FACE OF DISCRIMINATION AND VIOLENCE AGAINST WOMEN
}

\author{
Reham SHALABY*
}

The Higher Institute of Applied Arts, Fifth Settlement, Egypt

\begin{abstract}
The issue of violence against women has occupied a prominent position at the international level, as efforts, initiatives and agreements have sought to work to achieve justice and equality between men and women, and to recognize women's rights and combat all forms of violence against them. The paintings of plastic art always express the prevailing issues in society, or reflect a widespread phenomenon in it. Among the issues that attracted the attention of artists is the issue of "combating violence against women.

Keywords

The Creative Role, Plastic Arts, Discrimination, Violence, Women.
\end{abstract}

\section{Introduction}

Discrimination and violence against women is a dreaded disease, it is the disease of the times, and only an intense momentum of thought and science, knowledge and culture, literature and art will sweep it away in front of it. Here we pause for a long time before the role of art specifically in facing discrimination and violence against women, and undermining its foundations, so it is not necessary. That some people imagine that art is a luxury work, and that its importance exceeds other tools, as the cultural factor, and at its heart, the arts are plastic arts, theatre, cinema and other visual tools

The image is the essence of visual arts, with the new language it produced, which captured the human's visual energy. It arrested his mind and imagination. The image is the meeting point of the arts. The picture has witnessed several artistic transformations that greatly affected the production of new concepts, which contributed to the enrichment of all cultural activities of new concepts, which contributed to the enrichment of all cultural activities.

Art formal issues are fundamental issues, and they were never invented by the owners of the curricula or from the illusions of thinkers, artists or philosophers. The interest in what is related to style or form in a particular era is always linked to what is going on in the era and its social conditions. This is because the problems of form do not appear except through the production of works of art that came as a container or a tool to express answers to the questions posed by this era or that.

\footnotetext{
* Corresponding author: info@ appliedarts.edu.eg
} 


\section{Research Problem:}

The research problem lies in trying to answer the following questions:

1- What is the relationship between the form and the content of plastic art in the face of discrimination and violence against women?

2- What are the most important elements of the form that contributed to highlighting the content of plastic art in the face of discrimination and violence against women?

\section{Research Methodology and Procedures}

Several artistic works, which dealt with confrontation, the research relies on the analytical method that includes an analysis of discrimination and violence against women.

In order to achieve the objectives of the study, the researcher used the Descriptive Methodology, the method of content analysis being more appropriate to achieve the goal through which he tries to describe the phenomenon - the subject of the research (the creative role of plastic arts in facing discrimination and violence against women, analyzing artistic works, and showing the relationship between its components. And the opinions that are raised about it, the processes it includes and the effects that it creates, and it is one of the forms of organized scientific analysis and interpretation to describe a specific phenomenon or problem and quantify it by collecting codified data and information about the phenomenon or problem, classifying it, analyzing it, and subjecting it to accurate studies.

It is the curriculum that studies a phenomenon, event or issue that currently exists from which information can be obtained that answers the study questions without the researcher's intervention in them, in order to describe and interpret the results of the study. 2 / The descriptive approach was used in this study to extract problems of designing and producing artistic works in the face of discrimination and violence against women. The use of the descriptive method is not limited to describing the phenomenon and gathering information and data about it. Rather, this information must be classified quantitatively and qualitatively, in order to reach an understanding of the relationships of these phenomena with other phenomena. The descriptive method does not aim to describe phenomena or describe reality as it is, but rather to reach conclusions that contribute to understanding and developing this reality.

Coordinated knowledge that arises from observation, study and experimentation, which is carried out with the aim of determining the nature and origins of the phenomenon that is subject to observation and study. This coordinated knowledge is produced by producing a clear scientific approach, and this research relied on the descriptive survey approach, which aims to describe the documentation of current situations or trends, that is, it explains what they really are. And apply an appropriate significance test, to determine the extent of confidence in the 
results of the study.

\section{The second topic}

\section{Definition of domestic violence against women:}

Gender-based violence that impairs women's enjoyment of human rights and fundamental freedoms under general international law, or under specific human rights conventions, or nullifies their enjoyment of those rights and freedoms.

Understanding violence against women as a human rights issue does not exclude other efforts such as education, health, development and criminal justice efforts. Rather, addressing violence against women as a human rights issue encourages a holistic and indivisible response, and adds a human rights dimension to the work of various sectors, as well as calls for strengthening And accelerate initiatives in all areas to prevent and eliminate violence against women. The Universal Declaration against All Forms of Violence Against Women provided a comprehensive definition of violence against women as any assault against women based on gender that causes physical, sexual or psychological harm or pain to women. It includes the threat of this assault, pressure, or arbitrary deprivation of freedoms, whether it occurs in the context of public or private life.

\section{Define form and content}

Herbert Reed sees that the image - or form - of the artwork is the form that the work took, and it is the form of the artwork. "Reed" believes that this form is made by the artist who bestows shape on something. And if he sees that the artist is not only that person who paints pictures, or plays music, or composes poetry.

As for "Jerome Stollnitz", he saw that form is the invaluable and distinctive value of art. Form clarifies, enriches, and regulates complexity, and unifies the structural elements of a work of art. The elements used by the artist are also arranged in such a way that they are of profound artistic value.

Likewise, form - according to Stolnitz, gives the work of art that overall character, and the selfcompleteness that makes it stand out from among the other aspects of the experience and appears to be a world in its own right.

And the form in the language is the form, the attribute, and the type, which is the geometric shape composed of the dimensions that define the ends of the body of the image of the wax hollowed out in the mold, it is its geometric shape.

The image may be called what is by which the thing actually occurs, and in this sense it refers to what the photographer draws with a pen or camera, or on the imagination of the object on the woman, or in the mind, or on the mention of the tangible thing absent from the good. His 
image. According to the philosophers, the image corresponds to the material, and it is what distinguishes a thing, if it is outside its image is external, and if it is in the mind its image is mental.

Form is an extension of a place "characterized by its borders, appearance, color, movements, and many other details. But if the organic organism that includes these differences appears to be sensory, then it is certainly not this variety and its forms from which it derives its existence." It has a real existence, what that is except because its different parts, which seem to us to be tangible things, combine to be a whole, so that the characteristics that make it up despite their differences from each other are in harmony that brings them closer together and makes them cooperate for one specific purpose.

The form organizes the elements of the artwork, and makes them into a holistic unit between which harmony and compatibility are common, so these elements can be perceived - as a whole - aesthetically. This unity is not an abstract teleology or service to a specific purpose.

If the form is the most difficult element upon which the artwork is based, it includes problems of a metaphysical nature. "It is not surprising, too, that form is the most ambiguous word in the language of art." The ability of the figure to carry out multiple functions in art, and to be a source of disparate values, is the same that makes this term impossible to define.

Perhaps this ambiguity comes from the broad field of the figure, and the diversity of trends and opinions around it, so we find there are those who put it in the forefront of the two minds, while we find others who add it to the content or expression.

We find among the thinkers who make the image the priority (in the eyes of the artist over the content. He puts the subject only in the second consideration, confident that his first task is to create a coherent world of living images. And if some aesthetics have defined art as the will of the image will to Form only because they understood that the artwork is in large part merely creating a group of formal relationships

This trend, which emphasizes the primacy of the image, places the essential role in art for organizing and arranging the material, and thus it raises the value of the aesthetic image and renders the rest of it a mere shadow of it or a result.

An artistic image is a complex phenomenon of form, and it is created above all from anthropomorphic details. They are in the graphic arts) the parts of the person's life being photographed, the parts of his outward appearance (portraiture), the surrounding environment, his actions and his sayings, and his relationships with other individuals. Photographer. This arrangement is achieved through the material means possessed by the artistic genre concerned to recreate life. 
With words, gestures, facial expressions, lines, colors, and diacritics form, content and a cycle in defining the characteristics of expression The plurality of meaning is one of the good features that are calculated for the semantic text in the ceramic plastic artwork, which includes vocabulary that is worked on with more openness, because it carries intense signs that lead to multiple interpretations.

(The plurality of the text is not due to the ambiguity of its levels. What can be called the harmonious multiplicity of connotations that make up the artwork usually resort to metaphors and symbols in expressing the concepts of the meaning of the text, and it is based on metaphoric vocabulary that intertwines with the vocabulary of the painting, statue, or ceramic piece, so the substitution or the metaphor of meaning is the focus of the work. The technical meaning is to move it from the text of the ability to the recipient's presentation (), since the language of the artwork is not necessarily verbal, but there are other systems of semantics, if any, that offer a number of possible readings.

The most prominent thing that can be used in the artwork, when the meaning of the textual singular is transformed into specific connotations within the structure of the text, and this gives it an artistic formula capable of being transformed into signs, elements that are formed according to a pattern and system through which it appears through the system of displaying the artwork (it has a high expressive power The sense of the interconnectedness of the signifier and the signified is undermined when forming.

The signifier searches for the meaning of a variable that is not the dominant one and thus the signifier moves away from the circle of the fixed signified.

This moving away from the circle of fixed meanings, generating new meanings in a semantic way through, injecting new ideas, which increases the multiplicity of readings and the breadth of the space of interpretation, and also takes the pattern of sequential movement, (the permanent generation of signifiers within the field of the text is not done according to organic growth or in a manner Just interpretation, but according to a sequential movement of interference and change).

The plastic artist (the sculptor) specifically when he chooses his artistic product, and the vocabulary of the text with specific connotations, he realizes the mechanisms of the text's connection with the special vision, and works to perform some kind of operations that remove the complexity in the work itself, since the ceramic work needs some kind of operations, equations and experiments to extract color oxides or even access To the degrees of burning proportional to the type of material (clay or bronze), and here the processes of damage, unity and harmony appear to the researcher in the field of sculpture is required because it contributes 
to the involvement of a kind of imagination, to compose a new text within the plastic artwork, this focus on the idea, it gives an opportunity to highlight the details It may also be a producer of value, by filling the gaps of the text, with ideas of semantic value, and these are according to the interpretation of the recipient who in turn exports the signs and signals, and these cannot leave the text of the work, by breaking into the formed text, which exceeds the functional level and enters the level Suggestive.

This new establishment was done according to semantics, perhaps I worked in the circle of beauty, in order for the work to try to read according to new areas formed that produce meaning, so the process of connotation is directed within the work, and the connotations are subject to the recipient of the meaning through that same sign.

The researcher believes that the significance is in reading the text of the ceramic plastic work in terms of producing the meaning. The symbol leads to suggestion and in turn leads to interpretation. This sequence is one of the data that the recipient has when reading the text, and his tools are not only raw materials, but there are generative tools that he uses by means of semantics. The text refers to suggesting renewed interpretations, meaning that we can expand the text when the artist confronts vocabulary with new connotations and new cultures that distinguish him, in order to reach the meanings of the text created by the meaning of the work. Significance in the plastic artwork, especially ceramics in particular, is characterized by the escalation of meaning, that is, the formation of an image in the mind of the artist, and then it is passed through a number of necessities needed by the work itself, away from the raw materials to form a meaning that develops the structure of the work richer in ideas, so the sign is a series of The processes share the level of understanding when they depend on the senses, (it begins with perception, which is the first level that depends on the senses of the recipient, then recognition as a mental process, and then follows that the level of understanding that helps decipher the signs and arrive at a sign), the first axis: the significance of the shape in Artistic expression, and setting it has three variables.

1 - Is there a role in the contrasts and tonalities of the artwork?

2- Is there a diversity in the features of expression in plastic art in the face of discrimination and violence against women?

3- Does material have a role in creative expression, about the contemporary intellectual content in the plastic artist's achievement in the face of discrimination and violence against women? The second axis: the significance of content in artistic expression, and four variables were developed for it.

1- Does form play an essential role in expressing intellectual content? . 
2- Do artistic symbols lead to expressive significance in artwork? .

3- Do geometric shapes have expressive connotations in the artwork? .

4- Does the form sign work in the success of the intellectual and aesthetic communication process for plastic work in the face of discrimination and violence against women?

\section{Results}

1- The contemporary artist has sought to achieve diversity in the expression features of plastic art in the face of discrimination and violence against women? .

2- Artistic symbols play a role in the creative expression of the intellectual content in the plastic work of artists.

3- Contrasts and tones play a role in the creative expression of the artwork?

4- The contemporary artist is interested in geometric shapes to achieve the intellectual and aesthetic dimensions of plastic art in the face of discrimination and violence against women?

5- The contemporary artist emphasized the expressive features of shapes, and the combination of reality and symbol, investigating special expressive features of plastic art in the face of discrimination and violence against women.

6- The contemporary artist adopted the emphasis on the method of harmony or contradiction in a single work.

\section{References}

1- May Al-Eid Allah, Research in Information and Communication Sciences (Dar Al-Nahda Al-Arabiya, Beirut, 1211, ed 41), p .: 114.

2- Muhammad Munir Hijab, Front of Media and Social Research (Dar Al-Fajr for Publishing and Distribution, 2006

3- Abd al-Basit Muhammad al-Hasan, The Fundamentals of Social Research (Cairo Library, p. 12.

4- Shaima Zulfiqar, Research Methods and Statistical Uses in Media Studies, (The Egyptian Lebanese House, Cairo, 1222, 1st Edition) p: 11.

5- Deopold B. Van Dallen, Research Methods in Education and Psychology, translated by Muhammad Nabil Nofal and others (Cairo: The Anglo-Egyptian Library, 5th Edition), pp. 348349.

6- Herbert Read: Education through Art - translated by Abdel Aziz Tawfiq Jaweed - Revision by Mustafa Taha Habib - The Egyptian General Book Organization - Cairo - 1996 - p.25.

7- Jerome Stollnitz: Art Criticism - Aesthetic and Philosophical Study - Translated by Fouad Zakaria - General Egyptian Book Organization - Second Edition - Cairo - 1980 - p. 239.

8- Roland Barthes, studied semiology, translated by Abd al-Salam Benabid, al-Mandab (Dar 
Weqal for Thought and Publishing, 1986 AD), p.62.

9- Ferdinand Saussure, Lessons in General Linguistics, translated by Joel Yusef, (House of General Cultural Affairs, Iraq, Baghdad 1986 AD), p. 24.

10- Morris Abu Nazer, The Science of Linguistic Semantics, Journal of Contemporary Arab Thought (Center for Arab Development Issue 18-19 Beirut 1982 AD), p. 245.

11- Awad Ali, Blades of the Body (Azmana Publishing House, Amman, Jordan, 1996 AD)

12- Ahmad Bouhassan, The Theory of Receptivity, Problems and Applications, (Publications of the Faculty of Arts, 1st Edition, P151. Morocco, Casablanca).

13- Salih, Qasim Hussain, in the Psychology of Plastic Art, House of General Cultural Affairs, Baghdad, Edition 1, 1990), p. 167.

14- Shawkat Al-Rubaie, Contemporary Plastic Art in the Arab World, (Dara for Cultural Affairs, Baghdad, 1986), p. 79.

15- Jamil Saliba: The Philosophical Dictionary of the Lebanese House of Book - First Edition - Beirut - 1971), pp. 741-745.16.

16- Abd al-Rahman Badawi, Hegel's Philosophy of Beauty and Art (Dar Al-Shorouk - First Edition - Cairo - 1996), p. 66.

17- Gennady Perseplov, Artistic Beauty, translated by Adnan Jamous, International Critical Studies (11), (Syrian Ministry of Culture Publications, Damascus, 1991), p. 397.

18- Sarah Mohamed Abdel Nasser JABER, POSITIVE IMAGE OF WOMEN IN THE EGYPTIAN ADVERTISEMENT, International Journal of Humanities and Language Research, Vol. 2, No. 1, 2019, pp. 1-4.

Received: July 23, 2019

Accepted: September 30, 2019 